Wright State University

CORE Scholar

$9-1-2008$

\title{
Surface Traps in Vapor-Phase-Grown Bulk ZnO Studied by Deep Level Transient Spectroscopy
}

\author{
Z-Q. Fang \\ B. Claflin \\ David C. Look \\ Wright State University - Main Campus, david.look@wright.edu \\ Y. F. Dong \\ H. L. Mosbacker
}

See next page for additional authors

Follow this and additional works at: https://corescholar.libraries.wright.edu/physics

Part of the Physics Commons

\section{Repository Citation}

Fang, Z., Claflin, B., Look, D. C., Dong, Y. F., Mosbacker, H. L., \& Brillson, L. J. (2008). Surface Traps in Vapor-Phase-Grown Bulk ZnO Studied by Deep Level Transient Spectroscopy. Journal of Applied Physics, 104 (6), 63707.

https://corescholar.libraries.wright.edu/physics/160

This Article is brought to you for free and open access by the Physics at CORE Scholar. It has been accepted for inclusion in Physics Faculty Publications by an authorized administrator of CORE Scholar. For more information, please contact library-corescholar@wright.edu. 
Authors

Z-Q. Fang, B. Claflin, David C. Look, Y. F. Dong, H. L. Mosbacker, and L. J. Brillson 


\title{
Surface traps in vapor-phase-grown bulk ZnO studied by deep level transient spectroscopy
}

\author{
Z.-Q. Fang, ${ }^{1, a)}$ B. Claflin, ${ }^{1}$ D. C. Look, ${ }^{1}$ Y. F. Dong, ${ }^{2}$ H. L. Mosbacker, ${ }^{2}$ and L. J. Brillson ${ }^{2}$ \\ ${ }^{1}$ Semiconductor Research Center, Wright State University, Dayton, Ohio 45435, USA and Materials \\ and Manufacturing Directorate, Air Force Research Laboratory, Wright Patterson AFB, Ohio 45433, USA \\ ${ }^{2}$ Department of Electrical and Computer Engineering, The Ohio State University, Columbus, \\ Ohio 43210, USA
}

(Received 31 March 2008; accepted 18 July 2008; published online 23 September 2008)

\begin{abstract}
Deep level transient spectroscopy, current-voltage, and capacitance-voltage measurements are used to study interface traps in metal-on-bulk-ZnO Schottky barrier diodes (SBDs). $c$-axis-oriented ZnO samples were cut from two different vapor-phase-grown crystals, and $\mathrm{Au}$ - and Pd-SBDs were formed on their (0001) surfaces after remote oxygen-plasma treatment. As compared to Au-SBDs, the Pd-SBDs demonstrated higher reverse-bias leakage current and forward-bias current evidently due to higher carrier concentrations, which might have been caused by hydrogen in-diffusion through the thin Pd metal. The dominant traps included the well-known bulk traps $E_{3}(0.27 \mathrm{eV})$ and $E_{4}(0.49 \mathrm{eV})$. In addition, a surface-related trap, $E_{s}(0.49 \mathrm{eV})$, is observed but only in the Pd-SBDs, not in the Au-SBDs. Trap $E_{s}$ is located at depths less than about $95 \mathrm{~nm}$ and shows an electron capture behavior indicative of extended defects. A possible correspondence between trap $E_{s}$ and the well-known $2.45 \mathrm{eV}$ green band is suggested by depth-resolved cathodoluminescence spectroscopy on the same samples, which reveals an increase in the intensity of this band within $\sim 100 \mathrm{~nm}$ of the Pd/ZnO interface. (C) 2008 American Institute of Physics. [DOI: 10.1063/1.2978374]
\end{abstract}

\section{INTRODUCTION}

Crystalline $\mathrm{ZnO}$ has been studied extensively in recent years because of its unique properties that may enable a new generation of UV light emitters, UV photodetectors, and transparent transistors. ${ }^{1-3}$ To realize the potential of highperformance $\mathrm{ZnO}$-based optical and electronic devices, the formation of high quality metal/ZnO Schottky contacts is essential and many different metals such as $\mathrm{Au}, \mathrm{Ag}, \mathrm{Pd}$, and Pt have been investigated. ${ }^{4}$ Surface preparation prior to metal deposition is also important and various procedures such as oxygen plasma treatment, ${ }^{5,6}$ organic solvent cleaning, ${ }^{4,7}$ hydrogen peroxide treatment, ${ }^{8}$ and even $\mathrm{KrF}$ excimer laser irradiation ${ }^{9}$ have been attempted. However, not all of these efforts have been successful and many reported Schottky barrier diodes (SBDs) still show high reverse leakage currents, low Schottky barrier heights (SBHs), and high ideality factors ( $n$ 's). Some of the quality issues have been correlated to near-surface defects, which can even be present in asreceived $\mathrm{ZnO}$ substrates. The effects of near-surface or nearinterface defects on the quality of $\mathrm{ZnO}$ Schottky barriers have been well characterized by applying depth-resolved cathodoluminescence spectroscopy (DRCLS) in conjunction with current-voltage measurements. ${ }^{10}$ Complementary to these optical studies, deep level transient spectroscopy (DLTS) has been used by several groups to investigate electron traps such as $E_{3}$ at $0.29-0.30 \mathrm{eV}$ and $E_{4}$ at $0.53 \mathrm{eV}$ in bulk $\mathrm{ZnO}$ crystals, and possible correlations with various point defects have been noted. ${ }^{11-16}$ In this work, we have performed temperature-dependent current-voltage $(I-V)$, capacitance-voltage $(C-V)$, and DLTS measurements on Au/

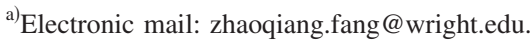

$\mathrm{ZnO}$ and $\mathrm{Pd} / \mathrm{ZnO}$ SBDs. The bulk $\mathrm{ZnO}$ crystal was grown by the vapor-phase process and was treated by remote oxygen plasma prior to metallization. In general, the electrical quality of the Pd-SBDs was found to be poorer than that of the $\mathrm{Au}-\mathrm{SBDs}$ due to the higher carrier concentrations in the former, which might be caused by hydrogen in-diffusion through the thin $\mathrm{Pd}$ layers. In addition to the welldocumented electron traps $E_{3}(0.30 \mathrm{eV})$ and $E_{4}(0.53 \mathrm{eV})$, we have observed a surface trap $E_{s}(0.49 \mathrm{eV})$ in Pd-SBDs, but not in Au-SBDs (at least, not yet measured). Trap $E_{s}$ is confined to a region within about $100 \mathrm{~nm}$ of the surface and shows an electron capture behavior indicative of extended defects.

\section{EXPERIMENTS}

The samples (ZNT-1 and ZNT-2, cut from the same bunch of substrates supplied by ZN Technology Inc.) were of size of $5 \times 5 \mathrm{~mm}^{2}$ with the (0001) $\mathrm{Zn}$ face up. Typical values of $300 \mathrm{~K}$ carrier concentration and mobility of such samples are about $5 \times 10^{16} \mathrm{~cm}^{-3}$ and $220 \mathrm{~cm}^{2} / \mathrm{V} \mathrm{s}$, respectively, and a typical maximum mobility at about $50 \mathrm{~K}$ is about $2000 \mathrm{~cm}^{2} / \mathrm{V} \mathrm{s}$, denoting excellent quality ${ }^{17}$ (however, we did not attempt to perform Hall-effect measurements on the samples used in the study). The samples were first chemically cleaned with organic solvents and then were loaded into an ultrahigh vacuum chamber (with a base pressure of $\sim 5 \times 10^{-9}$ Torr) and processed with remote $20 \%$ oxygen$80 \%$ helium plasma (ROP) at $40 \mathrm{~W}$ for $1 \mathrm{~h}^{6}{ }^{6}$ Without breaking vacuum, $\mathrm{Au}$ and $\mathrm{Pd}$ circular contacts $(30 \mathrm{~nm}$ thick and $0.4 \mathrm{~mm}$ in diameter) were deposited in situ on the $\mathrm{Zn}$ face of sample ZNT-1 by electron beam evaporation (Mantis EV) using a removable mask, while on ZNT-2, only Pd circular 


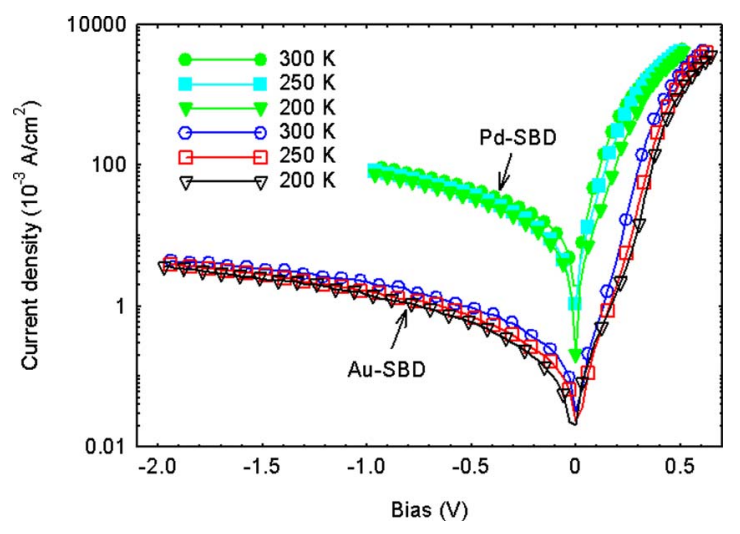

FIG. 1. (Color online) Typical temperature-dependent $I-V$ characteristics for $\mathrm{Au}-$ and Pd-SBDs fabricated on ROP-treated $\mathrm{ZnO}$. The SBD area is $0.125 \mathrm{~mm}^{2}$.

contacts were deposited to double-check the surface trap $E_{s}$. There is a small difference in the real contact area for Auand Pd-Schottky contacts due to different incident angles from their respective metal sources. Therefore, more accurate contact areas were determined by the use of scanning electron microscopy and cathodoluminescence mapping.

For $I-V$ and $C-V$ measurements, the Ohmic contact consisted of an In dot soldered onto the top corner of the sample and $\mathrm{Au}$ probes were used to contact the individual Schottky contacts. The $C-V$ and DLTS measurements were performed with an Accent DL8000 spectrometer, operated at a frequency of $1 \mathrm{MHz}$ for the capacitance measurements. The $I-V$ measurement was carried out with a current amplifier in the spectrometer. Carrier concentration profiles were determined from bias-dependent $C-V$ data and the DLTS spectra were obtained from the Fourier transforms of capacitance transients as temperature was swept from 100 to $300 \mathrm{~K}$. $I-V$ and $C-V$ characteristics were also determined over the temperature range from 200 to $300 \mathrm{~K}$. To test the possible influence of series resistance on the $I-V$ and $C-V$ data, due to the use of a top-surface In Ohmic contact, back-surface Ti/Au Ohmic contacts were also fabricated in some cases, forming a sandwich structure. Negligible differences were found probably due to the low bulk resistivity of the $\mathrm{ZnO}(\sim 0.6 \Omega \mathrm{cm})$.

\section{RESULTS AND DISCUSSION}

To determine uniformity, approximately six SBDs of each metal type were measured at room temperature on each sample. In general, the Au-SBDs showed better quality (e.g., lower reverse-bias leakage current and forward-bias current) than those formed from Pd. Typical $I$ - $V$ curves, measured at temperatures of 200-300 K, are presented in Fig. 1. If we assume that the forward current is dominated by thermionic emission (TE), then for $V>3 k T$ the current is given by $I$ $=I_{S}\left\{\exp \left[q\left(V-I R_{S}\right) / n k T\right]-1\right\}$, where the saturation current $I_{S}$ obeys $I_{S}=A A^{*} T^{2} \exp \left(-q \Phi_{B} / k T\right), R_{S}$ is the series resistance, $n$ is the ideality factor, $A$ is the diode area, $A^{*}$ is the effective Richardson constant $\left(32 \mathrm{~A} \mathrm{~cm}^{-2} \mathrm{~K}^{-2}\right)$, and $\Phi_{B}$ the zerobiased SBH. By using a TE model from the $I-V$ characteristics at $300 \mathrm{~K}$, the effective barrier heights for $\mathrm{Au}$ and $\mathrm{Pd}$ diodes were extracted to be $\Phi_{B}=0.68 \mathrm{eV}$ and $n=1.29 \mathrm{eV}$ for the Au-SBD and $\Phi_{B}=0.51 \mathrm{eV}$ and $n=1.67$ for the Pd-

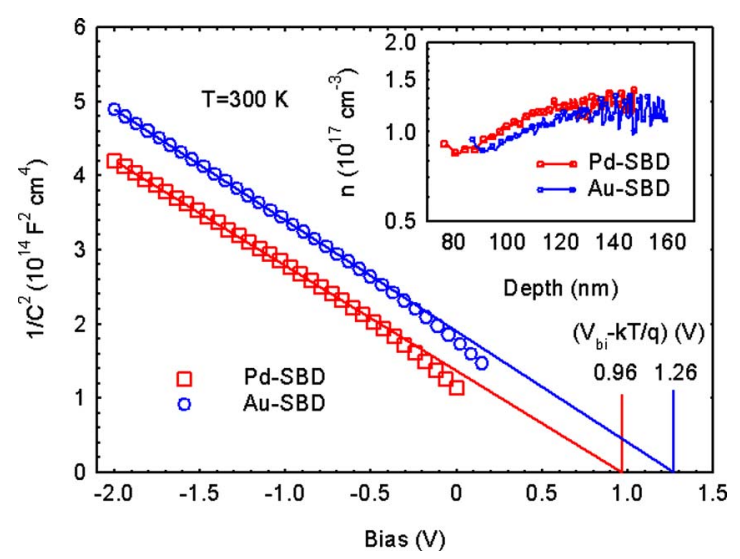

FIG. 2. (Color online) Typical $1 / C^{2}-V$ curves at $300 \mathrm{~K}$ for Au- and PdSBDs with associated carrier-concentration profiles shown in the inset.

SBD. The SBH for the Au-SBD is close to the literature value $;{ }^{4}$ however, the SBH for the Pd-SBD is much lower than typical values reported in the literature, such as 0.83 (Ref. 18) and $1.16 \mathrm{eV} .^{19}$ The difference could be due to some bulk properties of the substrate (e.g., carrier concentration) or to interface properties (e.g., interface traps).

In Fig. 1 we also note that both Au- and Pd-SBDs exhibit the following behavior: (i) the reverse currents are strongly dependent on bias but almost independent of temperature, which could be characteristic of tunneling conduction, and (ii) the forward currents at lower biases are also influenced by the possible tunneling conduction since TE conduction alone, corrected for series resistance, would give a straight line over the whole bias range. Clearly, both reverse and forward currents in the Pd-SBD are higher than those in the Au-SBD. However, the small tunneling parameter $E_{00}$ (a bulk property) of the $\mathrm{ZnO}$ samples, $E_{00} / k T \sim 0.1$ at $T$ $=300 \mathrm{~K}$, cannot account for the large leakage current, which indicates that other mechanisms such as hopping transport and/or a conductive surface layer play more important roles. In addition, we cannot rule out that the high reverse current in both SBDs could be related to localized current paths, which can be enhanced in a high electric field (producing, e.g., field-enhanced permanent soft breakdown). The enhancement in the reverse current with increasing reverse bias has been confirmed in recent experiments for both $\mathrm{Au}-$ and Pd-SBDs on similar ZNT samples with metallization on either the $\mathrm{Zn}$ or $\mathrm{O}$ face. Interestingly, the higher quality of Au-SBDs compared to Pd-SBDs was also reported for meltgrown $\mathrm{ZnO}$ (on both $\mathrm{O}$ and $\mathrm{Zn}$ faces) by Allen et al. ${ }^{4}$ using a similar TE analysis for their $I-V$ curves at RT.

The $C$ - $V$ curves for both Au- and Pd-SBDs are only weakly temperature dependent from 200 to $300 \mathrm{~K}$ so only $1 / C^{2}$ versus $V$ and associated depth-dependent carrier concentration curves are presented in Fig. 2. From the forward $I-V$ curve, the series resistance $\left(R_{S}\right)$ is determined to be $\sim 50 \Omega$ for both $\mathrm{Au}-$ and Pd-SBDs. The criterion $R_{s}$ $\ll(\omega C)^{-1}$ for the accurate determination of depletion capacitance can be satisfied at a frequency of $1 \mathrm{MHz}$. It can be seen from Fig. 2 that (i) over the depletion region, the carrier concentration in the Pd-SBD is higher than that in the AuSBD, e.g., $\sim 1.25 \times 10^{17}$ versus $\sim 1.15 \times 10^{17} \mathrm{~cm}^{-3}$ at the 


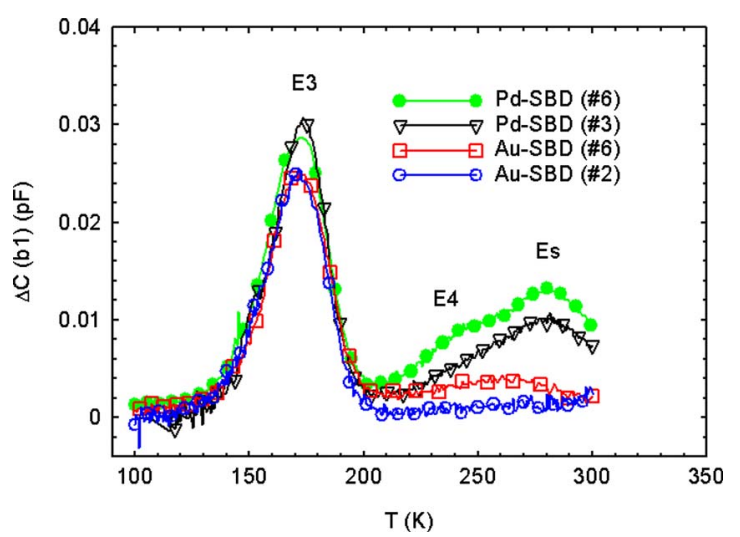

FIG. 3. (Color online) DLTS spectra for two Au-SBDs and two Pd-SBDs, measured under the following conditions: reverse bias $U_{R}=-0.5 \mathrm{~V}$, filling pulse height $U_{P}=0.1 \mathrm{~V}$, filling pulse width $t_{P}=1 \mathrm{~ms}$, and transient period $T_{W}=20.5 \mathrm{~ms}$.

depth of $140 \mathrm{~nm}$, (ii) at the same bias, a shallower depth (as low as $80 \mathrm{~nm}$ ) can be measured in the Pd-SBD due to its higher carrier concentration, (iii) carrier concentration for both SBDs was gradually decreased by about $30 \%$ as detected region towards the surface, and (iv) the built-in potential $\left(V_{\mathrm{bi}}\right)$ estimated from extrapolation of the $1 / C^{2}$ versus $V$ plot is $\sim 1.26 \mathrm{~V}$ for the Au-SBD and $\sim 0.96 \mathrm{~V}$ for the Pd$\mathrm{SBD}$, which gives more reasonable $\mathrm{SBH}$ values than those obtained from TE analysis of $I-V$ curves. The higher carrier concentration in the Pd-SBD is a general result for this set of samples. This behavior may be due to the incorporation of more hydrogen in the Pd-SBDs since it is well known that hydrogen can easily penetrate thin layers of $\mathrm{Pd}$. The higher carrier concentration leads to a thinner Schottky barrier and a higher electric field in depletion region, which could promote either stronger tunneling through the barrier or more fieldenhanced localized current paths.

The observation of a carrier concentration decrease towards the surface for both SBDs is very similar to that reported for both the $\mathrm{O}$ and $\mathrm{Zn}$ faces of $\mathrm{ZnO}$ treated with hydrogen peroxide. ${ }^{8,21}$ The decrease was attributed to the possible formation of a defective layer of $\mathrm{Zn}$ vacancies or vacancy clusters acting as compensating centers. ${ }^{8}$ However, in our recent experiments using similar ZNT samples with ROP treatment and Ohmic contact on the back, we observed carrier concentration decreases for both $\mathrm{Au}-$ and Pd-SBDs only on the $\mathrm{Zn}$ face, but not on the $\mathrm{O}$ face. ${ }^{20}$ Further studies are necessary to clarify the origin of this decrease. In addition, our most recent low-temperature photoluminescence (PL) (at $\sim 80 \mathrm{~K}$ ) spectra on a similar Zn face ZNT sample show an enhanced bound exciton emission $I_{4}(\sim 3.36 \mathrm{eV}$ at $80 \mathrm{~K}$ ) for Pd-SBDs, as compared to Au-SBDs and the bare surface $;^{20}$ this observation seems to support the in-diffusion of hydrogen at Pd-SBDs since $I_{4}$ is normally assigned to a neutral hydrogen donor bound exciton.

Figure 3 shows typical DLTS spectra, measured on two Au-SBDs and two Pd-SBDs. The experimental parameters are bias $U_{R}=-0.5 \mathrm{~V}$, filling pulse height $U_{P}=0.1 \mathrm{~V}$, filling pulse width $t_{P}=1 \mathrm{~ms}$, and transient period $T_{W}=20.48 \mathrm{~ms}$. From the figure, we see that (i) the dominant trap $E_{3}$ at 175 $\mathrm{K}$ has a density of about $(4-5) \times 10^{14} \mathrm{~cm}^{-3}$ in both types of
SBD, (ii) trap $E_{s}$ displaying a broad peak at $280 \mathrm{~K}$ can be only found in the Pd-SBDs, (iii) a weak trap $E_{4}$ appears at $\sim 240 \mathrm{~K}$ as a shoulder on trap $E_{s}$ in the Pd-SBDs, and (iv) trap $E_{4}$ actually appears at $260 \mathrm{~K}$ in one of the Au-SBDs. Note that $E_{4}$ was not observed in the other Au-SBD; however, it clearly appears at $260 \mathrm{~K}$ after baking at $440 \mathrm{~K}$ for 3 min in vacuum. The observation of $E_{s}$ in only the Pd-SBDs might be due to differences in the region of detection. That is, with applying a similar forward-going filling pulse height $\left(U_{P}=0.1 \mathrm{~V}\right)$ for both types of SBD, the detected region for the Pd-SBDs is shallower than that for the Au-SBDs (i.e., about 80 versus $100 \mathrm{~nm}$ below the surface). On one of the Pd-SBDs, we also measured DLTS as a function of $U_{P}$ at $U_{R}=-0.5 \mathrm{~V}$ (not shown here) and found that (i) with decreasing $U_{P}$ from 0.2 to $-0.1 \mathrm{~V}$ (i.e., decreasing the detected region near the surface), the peak height of $E_{s}$ decreases much faster than that of $E_{3}$ and (ii) at $U_{P}=-0.1 \mathrm{~V}$ only $E_{3}$ (i.e., no $E_{s}$ ) can be observed. This result suggests that $E_{s}$ is likely a trap located in the surface region only. For a further indication of whether these traps are located throughout the bulk or only in the surface region, we used a DLTS technique that was developed to study near-surface traps in semiconductors and applied to study surface-damage related traps in freestanding $\mathrm{GaN}$ after reactive ion-beam etching. ${ }^{22}$ In this technique, the DLTS spectrum is measured at different reverse biases while keeping the filling pulse height fixed. The basis of this method is that a more negative value of bias $U_{R}$, which translates to a higher detected sample volume, will naturally lead to a higher detected trap volume as long as the trap completely fills this sample region. This is the usual case in DLTS analysis, namely, the detection of uniform traps. However, if the particular trap fills only a region near the surface, then at some point $U_{R}$ will become negative enough that the detected sample volume is larger than the trap volume, and from then on, the DLTS signal volume will decrease with more negative $U_{R}$. At this value of $U_{R}$, the calculated depletion depth is the same as the maximum depth of the traps. ${ }^{22}$ DLTS signals, represented by apparent trap density $N_{T}$, for a typical Pd-SBD in sample ZNT-1, measured at a fixed $U_{P}=0.2 \mathrm{~V}$ but with a variable $U_{R}$ (from -2 to $-0.25 \mathrm{~V}$, corresponding to a detected depth from 160 to 95 $\mathrm{nm}$ ), are presented in Fig. 4. Here we see that trap $E_{3}$ continues to increase as $U_{R}$ becomes more negative; therefore, trap $E_{3}$ is a bulk trap. However, trap $E_{s}$ decreases for increasingly negative $U_{R}$ and thus $E_{s}$ is a near-surface trap. The situation for trap $E_{4}$, which is very weak, is uncertain. To further confirm the surface-trap nature of $E_{s}$, DLTS signal for a typical Pd-SBD in sample ZNT-2 was measured at different depths by using different combinations of $U_{R}$ and $U_{p}$, as shown in Fig. 5. Based on the standard calculation of depletion depth as a function of applied bias (not shown here), we estimate that trap $E_{3}$ can be observed at depths of at least 130 $\mathrm{nm}$ and probably much larger, whereas trap $E_{s}$ cannot be found at depths deeper than about $95 \mathrm{~nm}$. Thus, $E_{s}$ is a nearsurface trap.

In equilibrium, when the Fermi level just coincides with electron-trap energy $E_{T}$, the capture rate equals the emission rate $e_{n}$, resulting in the so-called principle of detailed balance $e_{n}=\sigma_{n} v_{\mathrm{th}} N_{C} \exp \left(E_{T}-E_{C} / k T\right)$, where $\sigma_{n}$ is the capture cross 


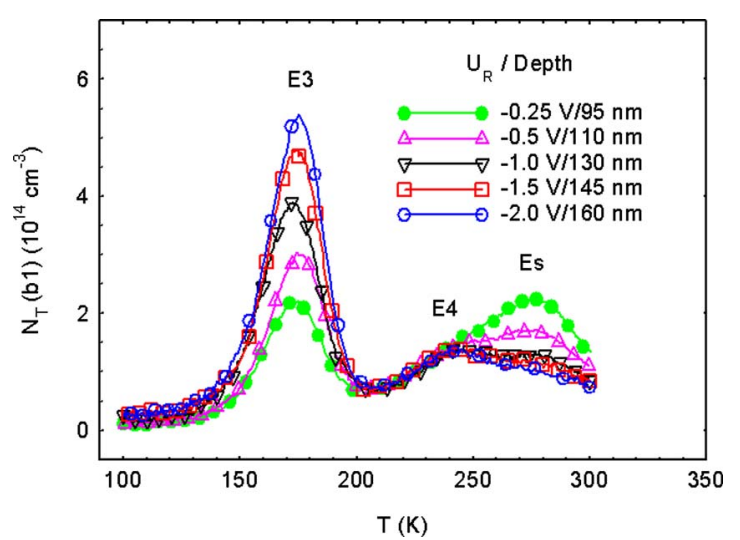

FIG. 4. (Color online) DLTS signal (represented by apparent trap density $N_{T}$ ) as a function of reverse bias $U_{R}$ for a Pd-SBD in sample ZNT-1. Conditions: $U_{R}=-0.25$ to $2.0 \mathrm{~V}, U_{P}=0.2 \mathrm{~V}, t_{P}=1 \mathrm{~ms}$, and $T_{W}=20.5 \mathrm{~ms}$. Corresponding detected depth: from 160 to $95 \mathrm{~nm}$.

section, $v_{\text {th }}$ the thermal velocity of electrons, $N_{C}$ the effective density of states at the bottom of the conduction band, $k_{B}$ the Boltzmann's constant, and $T$ the absolute temperature. In our Fourier-transform DLTS analysis, an Arrhenius plot of $\ln \left(e_{n}^{-1} v_{\mathrm{th}} N_{C}\right)$ for a given trap can be obtained by using the "maximum evaluation" method. This method is based on analysis of the temperature peak of a given trap in many different DLTS spectra, each obtained by applying different Fourier coefficients to the associated capacitance transient. Arrhenius plots of the various traps are shown in Fig. 6. For the Pd-SBD, traps $E_{3}$ and $E_{4}$ were analyzed from a DLTS spectrum measured at $U_{R}=-2.0 \mathrm{~V}$, corresponding to a detection depth of $\sim 160 \mathrm{~nm}$ (bulk region), while surface trap $E_{S}$ was analyzed from a DLTS spectrum at $U_{R}=-0.25 \mathrm{~V}$, corresponding to a detection depth of less than $95 \mathrm{~nm}$ from the surface (see Fig. 4). While for the Au-SBD, traps $E_{3}$ and $E_{4}$ were analyzed from a DLTS spectrum measured at $U_{R}$ $=0.5 \mathrm{~V}$ and $U_{P}=0.1 \mathrm{~V}$ (see Fig. 3). From analysis of the Arrhenius plots, we find that (i) trap $E_{3}$ has an energy $E_{T}$ of $0.27 \mathrm{eV}$ in both the Pd- and Au-SBDs but a slight difference in capture cross section $\sigma_{n}\left(1.6 \times 10^{-16} \mathrm{~cm}^{2}\right.$ in the Pd-SBD

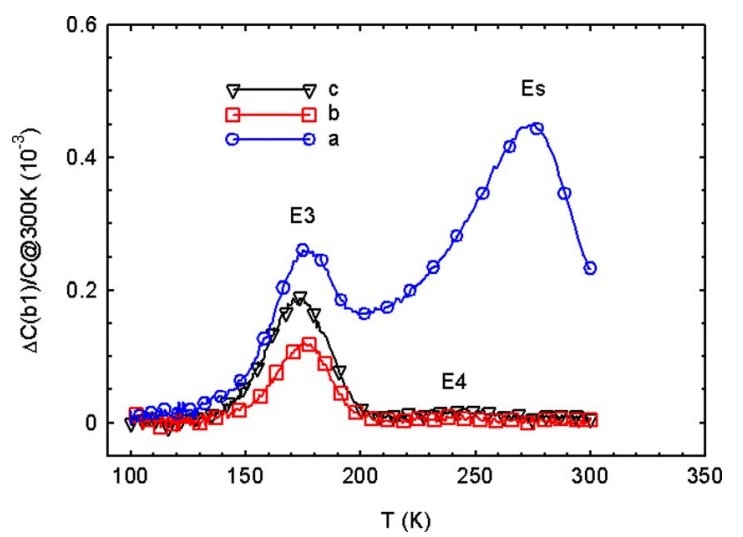

FIG. 5. (Color online) DLTS signal $(\Delta C / C)$ for a Pd-SBD in sample ZNT-2, measured in different depth windows by using different combinations of $U_{R}$ and $U_{P}$. (a) $U_{R}=-0.25 \mathrm{~V}$ and $U_{P}=0.2 \mathrm{~V}$ corresponding to a depth window of $\sim 60-95 \mathrm{~nm}$. (b) $U_{R}=-0.65 \mathrm{~V}$ and $U_{P}=-0.25 \mathrm{~V}$ corresponding to a depth window of $\sim 95$ to $115 \mathrm{~nm}$. (c) $U_{R}=-1.05 \mathrm{~V}$ and $U_{P}=-0.65 \mathrm{~V}$ corresponding to a depth window of $\sim 115$ to $130 \mathrm{~nm}$. Other conditions are $t_{P}=1 \mathrm{~ms}$ and $T_{W}=20.5 \mathrm{~ms}$.

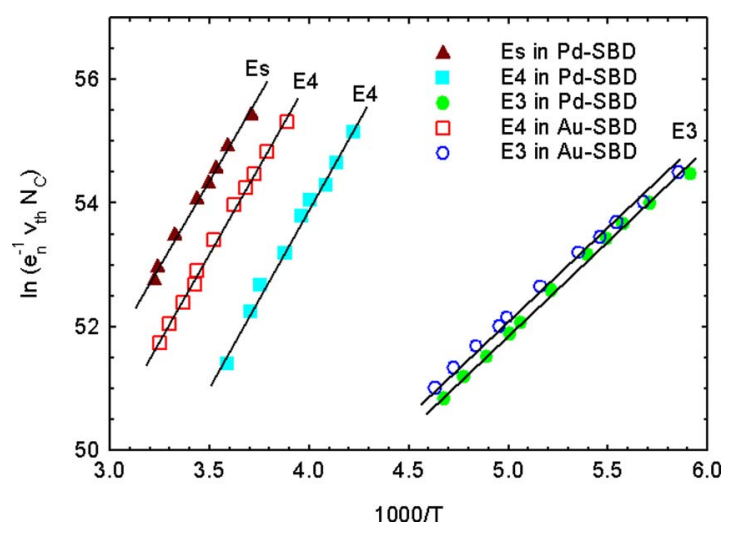

FIG. 6. (Color online) Arrhenius plots of $\ln \left(e_{n}^{-1} v_{\text {th }} N_{C}\right)$ for various traps in the Au-and Pd-SBDs.

versus $1.2 \times 10^{-16} \mathrm{~cm}^{2}$ in the Au-SBD), (ii) trap $E_{4}$ has $E_{T}$ $=0.49 \mathrm{eV}$ in both types of SBD, but significantly different capture cross sections $\left(\sigma_{n}=3.4 \times 10^{-14} \mathrm{~cm}^{2}\right.$ for the Pd-SBD and $3.5 \times 10^{-15} \mathrm{~cm}^{2}$ for the Au-SBD), and (iii) $E_{s}$ has $E_{T}$ $=0.49 \mathrm{eV}$ and $\sigma_{n}=5.2 \times 10^{-16} \mathrm{~cm}^{2}$ (for more information on the electron capture behavior of $E_{s}$, see below). In the literature, trap $E_{3}$ in vapor-phase-grown $\mathrm{ZnO}$ has been reported to have a trap concentration of $(1-2.2) \times 10^{14} \mathrm{~cm}^{-3}$, an activation energy of $0.29-0.30 \mathrm{eV}$, and a capture cross section of $(5.8-6.2) \times 10^{-16} \mathrm{~cm}^{2} .^{11,12}$ These values are very close to those determined for trap $E_{3}$ in this study. Also, these earlier studies found that, as compared to trap $E_{3}$, trap $E_{4}$ had a lower trap concentration, higher activation energy, and larger capture cross section, which are similar to the results of the present study. Trap $E_{3}$, which can be also found in crystals grown by the hydrothermal and melt techniques, has been variously assigned to the oxygen vacancy $V_{\mathrm{O}}$ (Ref. 11) or the zinc interstitial. ${ }^{13,16}$ On the other hand, trap $E_{4}$ has also been assigned to $V_{\mathrm{O}}$, based on a good correlation between the $E_{4}$ $(0.53 \mathrm{eV})$ concentration and the intensity of the PL green band at $2.45 \mathrm{eV}{ }^{14}$ However, trap $E_{s}$ has never been reported as a surface trap in previous DLTS studies on bulk $\mathrm{ZnO}$ crystals, including those grown by the vapor-phase, ${ }^{11,12}$ hydrothermal, ${ }^{13}$ or pressurized-melt ${ }^{15}$ methods.

Another interesting feature of trap $E_{s}$ is its dependence on filling pulse width. Figure 7 shows a set of DLTS spectra measured in the surface region $\left(U_{R}=-0.25 \mathrm{~V}\right.$ and $U_{P}$

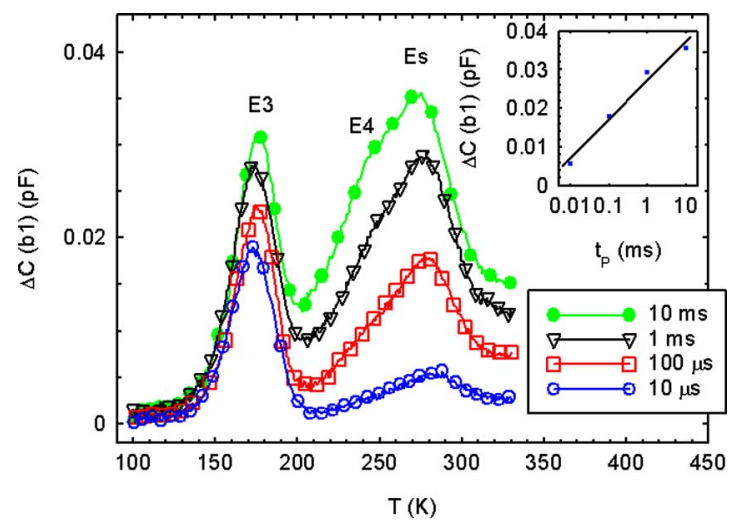

FIG. 7. (Color online) Near-surface DLTS spectra $\left(U_{R}=-0.25 \mathrm{~V}\right.$ and $U_{P}$ $=0.2 \mathrm{~V}$ ) as a function of filling pulse width for the Pd-SBD. 
$=0.2 \mathrm{~V})$ of the Pd-SBD, using a filling pulse width $\left(t_{P}\right)$ range of $10 \mu$ s to $10 \mathrm{~ms}$. The peak height of an isolated trap, such as $E_{3}$, is expected to saturate at high values of $t_{P}$, e.g., $10 \mathrm{~ms}$. However, note that the peak height of trap $E_{s}$ continues to increase significantly with increasing $t_{P}$, following a logarithmic behavior, as shown in the inset of Fig. 7. This logarithmic dependence is a prominent characteristic of traps that are associated with extended defects, such as threading dislocations in epitaxial $\mathrm{GaN}$ layers, ${ }^{23}$ microcracks in freestanding $\mathrm{GaN}^{24}$ and pores in porous $\mathrm{SiC}^{25}$ Therefore, it is likely that $E_{s}$ is associated with extended defects in the nearsurface region of bulk $\mathrm{ZnO}$. It may seem surprising that isolated trap $E_{3}$ in Fig. 7 also continues to increase slightly at $t_{P}=10 \mathrm{~ms}$; however, this behavior is likely artificial due to the "pulling up" of the baseline by the broad peak $E_{s}$, which is increasing rapidly with $t_{P}$. In fact, $E_{3}$ is known to have a capture cross section in the range of $10^{-16}-10^{-15} \mathrm{~cm}^{2}, 11,12,15$ and so it would be expected to reach saturation at $t_{P}$ $\sim 1 \mathrm{~ms}$. Indeed, we have measured the $E_{3}$ peak height versus $t_{P}$ in a bulk, melt-grown $\mathrm{ZnO}$ sample, which does not contain trap $E_{s}$, and have found that it saturates at $t_{P}$ $=1 \mathrm{~ms}$, consistent with its measured capture cross section of $\sigma_{n}=7 \times 10^{-16} \mathrm{~cm}^{2}{ }^{26}$ In addition to the commonly observed trap $E_{3}(0.3 \mathrm{eV})$, another close lying peak $E_{3}^{\prime}(0.37 \mathrm{eV})$ was observed by using high resolution Laplace-transform DLTS in $\mathrm{ZnO}$ grown by pulsed-laser deposition. ${ }^{27}$ An increase in the concentration of $E_{3}^{\prime}$ after annealing in oxygen suggested that the trap could be associated with $\mathrm{O}$. In that study, however, $E_{3}^{\prime}$ was not found in a bulk $\mathrm{ZnO}$ grown by the vaporphase technique (serving as a reference). A similar $E_{3} / E_{3}^{\prime}$ feature $(\sim 0.32 \mathrm{eV})$ was also reported in hydrothermally grown bulk $\mathrm{ZnO}$ for silver oxide Schottky contacts. ${ }^{13}$ In that study, the filling pulse width $\left(t_{P}\right)$ was varied from 1 to $10 \mu \mathrm{s}$ and the DLTS signal shifted to higher temperatures due to the contribution of $E_{3}^{\prime}$. In our study, however, the shift in $E_{3}$ (see Fig. 7) is mainly related to the direction of the thermal scans since the spectra measured at $t_{P}=100 \mu \mathrm{s}$ and $10 \mathrm{~ms}$ during the cooling scan both shift to slightly higher temperatures as compared to the two spectra measured at $t_{P}$ $=10 \mu \mathrm{s}$ and $1 \mathrm{~ms}$ during the warming scan. Further study would be needed to determine whether or not there really exists an $E_{3} / E_{3}^{\prime}$ feature in vapor-phase grown $\mathrm{ZnO}$.

Defects near surfaces and interfaces and their effects on metal/ZnO Schottky barriers have been earlier studied with the DRCLS technique. ${ }^{10,28}$ This type of experiment is especially powerful in conjunction with $I-V$ analysis and can help determine the most desirable combinations of substrate, metal, and surface treatment. The main conclusions of these studies are that (i) native point defects are present at and below the $\mathrm{ZnO}$ surface and strongly influence the diode rectification ratio and ideality factor, (ii) the magnitudes of the usual deep levels at $2.1,2.5$, or $3.0 \mathrm{eV}$, as measured by DRCLS, can vary by orders of magnitude depending on substrate growth technique, surface processing, and metallization, and (iii) some metals, such as Al, can induce chemical interactions with $\mathrm{ZnO}$, resulting in the formation of subsurface defects. In our present study, we have measured DRCLS on the $\mathrm{ZnO}$ bare surface and then after 30-nm-thick deposits of $\mathrm{Au}$ and $\mathrm{Pd}$, with all of the samples first subjected to ROP
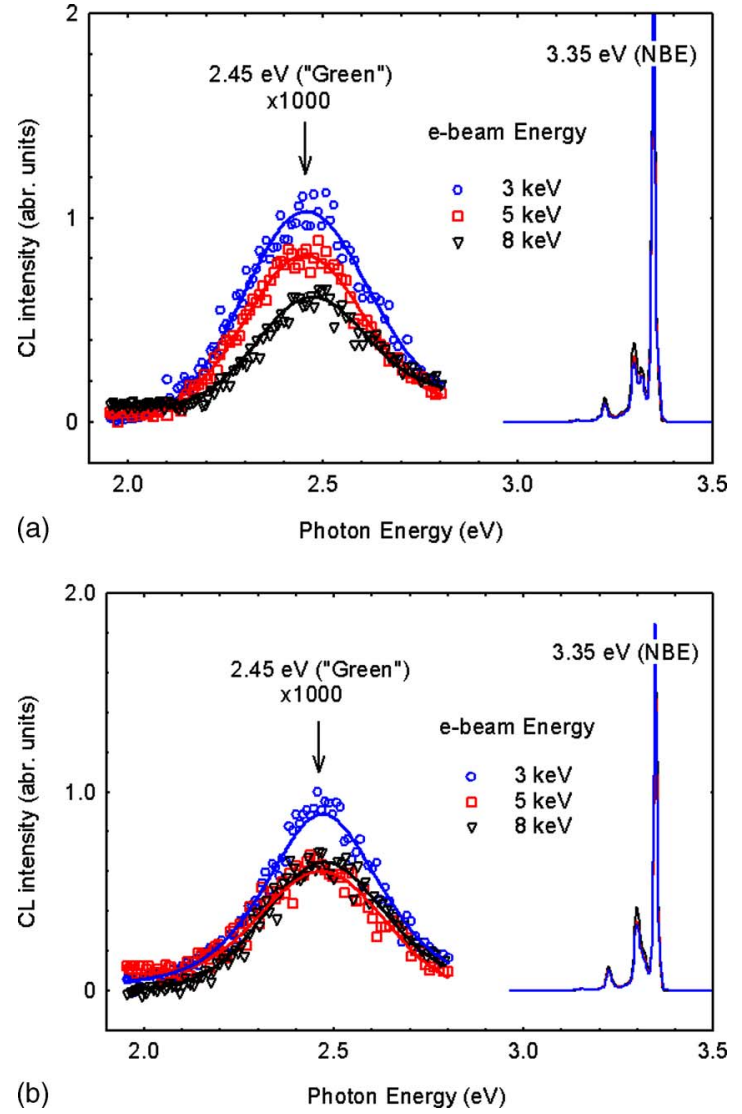

FIG. 8. (Color online) Normalized DRCL spectra of $\mathrm{Zn}$ face (a) $\mathrm{Pd}-\mathrm{ZnO}$ and (b) $\mathrm{Au}-\mathrm{ZnO}$ diodes. Defect vs NBE emission increases steadily with interface proximity for (a) but remains constant except at the interface $(<30 \mathrm{~nm})$ for $(\mathrm{b})$.

treatments. The relatively low-defect intensities shown in Fig. 8 show that the present $\mathrm{ZnO}$ samples belong to the "low-defect" category, as discussed in Ref. 28. Interestingly, we find significant changes in the deep level versus nearband-edge (NBE) emission intensities as a function of incident electron beam energy $\left(E_{b}=3-8 \mathrm{keV}\right)$ for the Pd-SBDs but not for the Au-SBDs, consistent with the DLTS results.

DRCLS for 30-nm-thick Pd- and Au-SBDs are shown in Figs. 8(a) and 8(b), respectively. When approaching from the bulk region (beam energy at $8 \mathrm{keV}$ with sampling depth $>100 \mathrm{~nm}$ below the interface) to the near-surface ( $5 \mathrm{keV}$, 20-70 nm) and surface region ( $3 \mathrm{keV},<20 \mathrm{~nm})$, the intensity of the $2.45 \mathrm{eV}$ defect peak increases by factors of 1.3 and 1.7, respectively, for Pd-SBDs. There is negligible change in the near-surface/bulk ratio of the $2.45 \mathrm{eV}$ peak for $\mathrm{Au}-\mathrm{SBD}$, although this peak does increase by a factor of 1.4 in the surface region. Thus, the depth distribution of the 2.45 $\mathrm{eV}$ peak revealed by DRCLS is very similar to that of DLTStrap $E_{s}$. If the $2.45 \mathrm{eV}$ peak is related to the $\mathrm{O}$ vacancy $V_{\mathrm{O}}$, as many speculate, then $E_{s}$ may also be related to $V_{\mathrm{O}}$, or a $V_{\mathrm{O}}$ complex such as $\mathrm{H}-V_{\mathrm{O}}$. The samples reported in Fig. 8 were annealed at $350{ }^{\circ} \mathrm{C}$ in Ar. The as-deposited samples show the same trend but with smaller changes in the $2.45 \mathrm{eV}$ peak. Interestingly, another group has also found a correlation between this $2.45 \mathrm{eV}$ emission and a trap but it is a different trap, $E_{4}(0.53 \mathrm{eV}) .{ }^{14}$ Pfisterer et al. ${ }^{29}$ associated a $2.45 \mathrm{eV} \mathrm{PL}$ peak with oxygen vacancies based on $\mathrm{O}$ annealing experi- 
ments. In turn, they show a reasonably good correlation of a $530 \mathrm{meV}_{4}$ defect with this $2.45 \mathrm{eV}$ emission and theory. ${ }^{29}$ This suggests a Franck-Condon shift of approximately $3.35 \mathrm{eV}-0.53 \mathrm{eV}-2.45 \mathrm{eV}=0.37 \mathrm{eV}$ between the DLTS and PL energies. It also implies that the $2.45 \mathrm{eV}$ feature in Fig. 8 corresponds to oxygen vacancies and $E_{s}$ might be a variant of $E_{4}$ (since they have similar activation energy but different capture cross sections).

It is possible that $E_{s}$ is indeed present in the $\mathrm{Au} / \mathrm{ZnO}$ sample but is too close to the surface to be detected by the DLTS experiment. In any case, further experiments on this issue are warranted. Also, the identity of $E_{s}$ and how it is created are still mysteries. It appears to be a defect induced by $\mathrm{Pd}$ but not by Au metallization, so other types of metallization should also be investigated. These issues must await further study.

\section{CONCLUSIONS}

In summary, $I-V, C-V$, DLTS, and DRCLS measurements were performed on thin $\mathrm{Au}$ - and Pd-SBDs fabricated on (0001) surfaces of vapor-phase-grown $\mathrm{ZnO}$ samples that had first been treated by remote oxygen plasma. The PdSBDs exhibit higher currents at high reverse biases and low forward biases, and in general, have poorer electrical quality. This difference in Schottky barrier quality may be related to more hydrogen in-diffusion through $\mathrm{Pd}$ than $\mathrm{Au}$, leading to higher carrier concentrations just below the metal. DLTS measurements reveal the well-known electron traps $E_{3}(0.27$ $\mathrm{eV})$ and $E_{4}(0.49 \mathrm{eV})$ in both the Pd- and Au-SBDs, but also a surface trap $E_{s}(0.49 \mathrm{eV})$ in the Pd-SBD only. Trap $E_{s}$ is located at depths less than $\sim 95 \mathrm{~nm}$ and shows a peculiar electron capture behavior, suggesting an association with extended defects. On the other hand, DRCLS measurements find a $2.45 \mathrm{eV}$ emission near the surfaces of both samples with a measureable increase for Pd diodes. Although our present measurements have not yet found an exact correlation between $E_{s}$ and the $2.45 \mathrm{eV}$ emission, further studies are warranted because the DLTS and DRCLS regions of detection may not overlap sufficiently in the Pd-SBD.

\section{ACKNOWLEDGMENTS}

We wish to thank H. E. Smith, E. R. Heller, and G. C. Farlow for helpful discussions. Support of Z.-Q.F., B.C., and D.C.L. was provided by NSF Grant No. DMR0513968 (L. Hess), ARO Grant No. W911NF-07-D-0001/Task07275 (M. Gerhold), AFOSR Grant No. FA9550-07-1-0013 (K. Reinhardt), and AFRL Contract No. FA8650-06-D-5401 (D. Silversmith). Both the Ohio State and Wright State groups gratefully acknowledge support by NSF Grant No. DMR0513968 (L. Hess).
${ }^{1}$ D. C. Look, J. Electron. Mater. 35, 1299 (2006).

${ }^{2}$ S. J. Pearton, D. P. Norton, K. Ip, Y. W. Heo, and T. Steiner, Prog. Mater. Sci. 50, 293 (2005).

${ }^{3}$ U. Ozgur, Y. I. Alivov, C. Liu, A. Teke, M. A. Reshchikov, S. Dogan, V. Avrutin, S. J. Cho, and H. Morkoc, J. Appl. Phys. 98, 041301 (2005).

${ }^{4}$ M. W. Allen, M. M. Alkaisi, and S. M. Durbin, Appl. Phys. Lett. 89, 103520 (2006)

${ }^{5}$ B. J. Coppa, R. F. Davis, and R. J. Nemanich, Appl. Phys. Lett. 82, 400 (2003).

${ }^{6}$ H. L. Mosbacker, Y. M. Strzhemechny, B. D. White, P. E. Smith, D. C. Look, D. C. Reynolds, C. W. Litton, and L. J. Brillson, Appl. Phys. Lett. 87, 012102 (2005).

${ }^{7}$ H. Endo, M. Sugibuchi, K. Takahashi, S. Goto, S. Sugimura, K. Hane, and Y. Kashiwaba, Appl. Phys. Lett. 90, 121906 (2007).

${ }^{8}$ R. Schifano, E. V. Monkhov, U. Grossner, and B. G. Svensson, Appl. Phys. Lett. 91, 193507 (2007).

${ }^{9}$ M.-S. Oh, D.-K. Hwang, J.-H. Lim, Y.-S. Choi, and S.-J. Park, Appl. Phys. Lett. 91, 042109 (2007).

${ }^{10}$ L. J. Brillson, H. L. Mosbacker, M. J. Hetzer, Y. Strzhemechny, G. H. Jessen, D. C. Look, G. Cantwell, J. Zhang, and J. J. Song, Appl. Phys. Lett. 90, 102116 (2007).

${ }^{11}$ F. D. Auret, S. A. Goodman, M. J. Legodi, W. E. Meyer, and D. C. Look, Appl. Phys. Lett. 80, 1340 (2002).

${ }^{12}$ H. von Wenckstern, M. Brandt, H. Schmidt, G. Biehne, R. Pickenhain, H. Hochmuth, M. Lorenz, and M. Grundmann, Appl. Phys. A: Mater. Sci. Process. 88, 135 (2007)

${ }^{13}$ H. von Wenckstern, H. Schmidt, M. Grundmann, M. W. Allen, P. Miller, R. J. Reeve, and S. M. Durbin, Appl. Phys. Lett. 91, 022913 (2007).

${ }^{14}$ D. Pfisterer, D. M. Hofmann, J. Sann, B. K. Meyer, R. Tena-Zaera, V. Munoz-Sanjose, Th. Frank, and G. Pensl, Physica B (Amsterdam) 376377, 767 (2006).

${ }^{15}$ F. D. Auret, J. M. Nel, M. Hayes, L. Wu, W. Wesch, and E. Wendler, Superlattices Microstruct. 39, 17 (2006).

${ }^{16} \mathrm{G}$. Brauer, W. Anwand, W. Skorupa, J. Kuriplach, O. Melikhova, C. Moisson, H. Von Wenckstern, H. Schmidt, M. Lorenz, and M. Grundmann, Phys. Rev. B 74, 045208 (2006).

${ }^{17}$ D. C. Look, Donors and Acceptors in Bulk ZnO Grown by Vapor-Phase, Melt, and Hydrothermal Processes, MRS Symposia Proceedings No. 957 (Materials Research Society, Pittsburgh, 2007), p. 127; D. C. Look, Surf. Sci. 601, 5315 (2007).

${ }^{18}$ U. Grossner, S. Gabrielsen, T. M. Børseth, J. Grillenberger, A. Y. Kuznetsov, and B. G. Svensson, Appl. Phys. Lett. 85, 2259 (2004).

${ }^{19}$ H. von Wenckstern, G. Biehne, R. A. Rahman, H. Hochmuth, M. Lorenz, and M. Grundmann, Appl. Phys. Lett. 88, 092102 (2006).

${ }^{20}$ Y. F. Dong, Z.-Q. Fang, D. C. Look, G. Cantwell, J. Zhang, J. J. Song, and L. J. Brillson, Appl. Phys. Lett. 93, 072111 (2008).

${ }^{21}$ S.-H. Kim, H.-K. Kim, S.-W. Jeong, and T.-Y. Seong, Superlattices Microstruct. 39, 211 (2006).

${ }^{22}$ D. C. Look and Z.-Q. Fang, Appl. Phys. Lett. 79, 84 (2001).

${ }^{23}$ Z.-Q. Fang, D. C. Look, and L. Polenta, J. Phys.: Condens. Matter 14, 13061 (2002).

${ }^{24}$ Z.-Q. Fang, D. C. Look, A. Krtschil, A. Krost, F. A. Khan, and I. Adesida, J. Electron. Mater. 35, 613 (2006).

${ }^{25}$ D. C. Look, Z.-Q. Fang, S. Soloviev, T. S. Sudarshan, and J. J. Boeckl, Phys. Rev. B 69, 195205 (2004).

${ }^{26}$ Z.-Q. Fang and H. L. Mosbacker (unpublished).

${ }^{27}$ F. D. Auret, W. E. Myer, P. J. Janse van Rensburg, M. Hayes, J. M. Nel, H. von Wenckstern, H. Schmidt, G. Biehne, H. Hochmuth, M. Lorenz, and M. Grundmann, Physica B (Amsterdam) 401-402, 378 (2007).

${ }^{28}$ H. L. Mosbacker, S. El Hage, M. Gonzalez, S. A. Ringel, M. Hetzer, D. C. Look, G. Cantwell, J. Zhang, J. J. Song, and L. J. Brillson, J. Vac. Sci. Technol. B 25, 1405 (2007); H. L. Mosbacker, C. Zgrabik, M. Hetzer, A. Swain, D. C. Look, G. Cantwell, J. Zhang, J. J. Song, and L. J. Brillson, Appl. Phys. Lett. 91, 072102 (2007).

${ }^{29}$ C. G. Van de Walle, Physica B (Amsterdam) 308-310, 899 (2001). 